The University of San Francisco

USF Scholarship: a digital repository @ Gleeson Library |

Geschke Center

Business Analytics and Information Systems

School of Management

$1-2015$

\title{
The Concept of "IT Artifact" Has Outlived Its Usefulness and Should Be Retired Now
}

Steven Alter

University of San Francisco, alter@usfca.edu

Follow this and additional works at: http://repository.usfca.edu/at

Part of the Business Commons

\section{Recommended Citation}

Alter, S. (2015). The concept of 'IT artifact'has outlived its usefulness and should be retired now. Information Systems Journal, 25(1), 47-60.

This Article is brought to you for free and open access by the School of Management at USF Scholarship: a digital repository @ Gleeson Library | Geschke Center. It has been accepted for inclusion in Business Analytics and Information Systems by an authorized administrator of USF Scholarship: a digital repository@Gleeson Library | Geschke Center. For more information, please contact repository@usfca.edu. 


\title{
The Concept of "IT Artifact" Has Outlived Its Usefulness and Should Be Retired Now
}

\author{
Steven Alter \\ University of San Francisco \\ alter@usfca.edu
}

\begin{abstract}
Vastly inconsistent definitions of the term "the IT artifact" in leading journals and conferences demonstrate why it no longer means anything in particular and should be retired from the active IS lexicon. Examples from the literature show why artifact-cousins, such as the IS artifact, sociotechnical artifact, social artifact, and ensemble artifact should be used with great care, if not retired as well. Any void created by these retirements could be filled through the following approaches: 1) relabeling with simple terms that are immediately understandable, 2) adopting guidelines for making sense of the whole $\mathrm{X}$-artifact family, and 3) sidestepping the IT artifact and focusing directly on IT-enabled work systems in organizations.
\end{abstract}

Keywords. IT artifact, IS artifact, social artifact, technical artifact, ensemble artifact, sociotechnical artifact 
'When I use a word,' Humpty Dumpty said, in rather a scornful tone, 'it means just what I choose it to mean - neither more nor less.'

Through the Looking Glass (Carroll, 1872)

\begin{abstract}
"This track calls for papers concerning the "IT artifact", where the IT artifact is understood as information technology (IT) (software, hardware, infrastructure, data communications), IT-enabled systems (information systems) and processes and methods associated with IT and IT-enabled systems development.”
\end{abstract}

Track Description, IT Artifact track, ICIS 2013.

While Humpty Dumpty can get away with saying that things mean whatever he chooses them to mean in a sequel to Lewis Carroll's Alice's Adventures in Wonderland, that approach is not appropriate for IS researchers, especially since the IS field espouses such great concern about combining rigor, relevance, and influence in the real world. The above excerpt from the Call for Papers of the IT Artifact track of ICIS 2013 says that the IT artifact is understood as any of three completely different kinds of things, technologies consisting of hardware and software, sociotechnical systems with human participants, and processes and methods. While common words such as cell and edge can have different but easily understandable meanings in different contexts, there is no reason why IS researchers need an ambiguous and mystifying label that tries to encompass just about anything that involves or touches IT in some way and that might be of interest to members of the IS research community.

My suggestion that "the IT artifact" should be retired is in the spirit of the Annual Question for 2014 at the website www.edge.org, "What scientific idea is ready for retirement?" Concepts whose retirements were suggested in comments to that website include artificial intelligence, essentialism, cause and effect, evidence-based medicine, and many others. (Overbye, 2014) In my opinion, retirement of "the IT artifact" is easier to justify.

This paper is divided into three sections. First, it shows that the previously meaningful term IT artifact no longer means anything in particular. It demonstrates that point by quoting vastly inconsistent definitions of IT artifact in Information Systems Research, MIS Quarterly, and other journals. Next, it identifies references to artifact-cousins of the IT artifact, such as the IS artifact, sociotechnical artifact, 
social artifact, and ensemble artifact. Based on the history of inconsistent uses of the term IT artifact, its artifact-cousins could even amplify confusion about whether the $\mathrm{X}$-artifact is an instance of $\mathrm{X}$ (e.g. texting on a smartphone), an effect or correlate of $\mathrm{X}$ (e.g., accidents while texting), or a concept related to $\mathrm{X}$ (e.g., smartphone obsession syndrome). Instead of continuing with the Humpty Dumpty approach of treating IT artifact and its various cousins as awkward labels for just about anything IS researchers are interested in, it would be better to retire the IT artifact and its cousins, eschew further debates about definitions and boundaries of the X-artifact, and focus more directly on achieving the IS discipline's espoused goals of rigor, relevance, and influence in the real world.

\section{The IT artifact no longer means anything in particular.}

The concept of IT artifact has morphed from being an entity consisting of hardware and software into the application of such an entity and further to just about anything that an IS researcher might be interested in. The concept was meaningful when first used, but has been re-interpreted and re-defined many times by researchers with different viewpoints, objectives, and research interests. At this point, the coexistence of many conflicting definitions has rendered the IT artifact meaningless, as is apparent from the following chronology.

The first widely cited reference to the IT artifact appeared in 1995 in a discussion of design research versus natural science research, where it seemed to mean an entity consisting of hardware and software. "Given an artifact whose performance has been evaluated, it is important to determine why and how the artifact worked or did not work within its environment. Such research applies natural science methods to IT artifacts. .... Theorizing in IT research must explicate those characteristics of the IT artifact operating in its environment that make it unique to IT and require unique explanations. (March \& Smith, 1995, p. 259)

Orlikowski \& Iacono (2001, p. 121) defined IT artifact in Information Systems Research in a parenthetical comment within a summary statement. "By and large, IT artifacts (bundles of material and cultural properties packaged in some socially recognizable form such as hardware and/or software.) continue to be under theorized." One of that influential paper's important contributions is a carefully justified argument that as of 2001 IT often seemed to be absent or superficially represented in much IS research. Foreshadowing future uses of the IT artifact 
concept and its cousin concepts, that paper also identified premises related to characteristics of IT artifacts, such as that they "are always embedded in some time, place, discourse, and community," they "emerge from ongoing social and economic practices," and they "are not static or unchanging, but dynamic.” (p. 131)

Several years later, a widely debated paper in MIS Quarterly viewed the IT artifact as the application of IT. "We conceptualize the IT artifact ... as the application of IT within a context to enable or support some task(s) embedded within a structure(s) that itself is embedded within a context(s)." (Benbasat \& Zmud, 2003, p. 186). That paper went on to say, "the four elements of an IT artifact include information technology, task, task structure, and task context (p. 188).

In one of many responses to Benbasat \& Zmud (2003), a 2005 MIS Quarterly paper "recommend[ed] expanding the definition of the IT artifact from 'enabling or supporting some tasks' to specify IT as the integration of the processing logic found in computers with the massive stores of databases and the connectivity of communications networks. The IT artifact includes IT infrastructure, innovations with technology, and especially the Internet." (Agarwal \& Lucas, 2005, p. 394)

Around the same time, a widely cited MIS Quarterly paper that argued for the legitimacy and importance of design science research included four types of design research topics that had been mentioned in March \& Smith (1995, p. 259). "IT artifacts are broadly defined as constructs (vocabulary and symbols), models (abstractions and representations), methods (algorithms and practices), and instantiations (implemented and prototype systems). (Hevner et al., 2004, p. 77).

In 2008 both a JAIS paper and an ICIS paper returned to treating IT artifacts as entities consisting of hardware and software. Markus \& Silver (2008, p. 620) said that "a given IT artifact comprises numerous technical objects, which may themselves be decomposed." Matook \& Brown, 2008, p. 2) defined "the components of an IT artifact by drawing on general systems theory and ontologies" ... "we describe the five IT artifact characteristics" (p. 5) [synchronous - asynchronous, integrated - standalone, adaptive - non-adaptive, static - dynamic, stateless stateful]

In 2011, the introduction to a special issue on design science research proposed an even broader definition than had been proposed in Hevner et al. (2004). "We argue toward a more expansive view of the IT artifact to include any designed solution that solves a problem in context" (Gregor \& Hevner, 2011, p. 4)

Several papers in 2013 moved in a different direction by asking whether IT artifacts are better understood in relation to artifact-cousins that will be discussed later. Silver \& Markus (2013, pp 82-83) said that "so-called "IT artifacts" have both 
technical and social design features and are therefore better regarded as "SocioTechnical (ST) artifacts". ... "We define the IT artifact as a sociotechnical assemblage." Goldkuhl (2013, p. 93-94) questioned that approach, saying that "an IT artifact is a physical artifact based on technology." ... "We do not need to put humans inside the boundary of the IT artifact in order to make these artifacts social." Lee et al. (2013, p. 1) took a different approach, saying "we 'unpack' what has been called the 'IT artifact' into a separate 'information artifact' and 'technology artifact' that, together with a 'social artifact,' interact to form the 'IS artifact."”

Finally, as noted in the introduction, the 2013 ICIS Track on IT Artifacts defined the IT artifact as three completely different types of things: "The IT artifact is understood as information technology, IT-enabled systems, or processes and methods associated with IT.” (ICIS 2013 website, 2013)

If IT artifact is a clear and meaningful concept, it should be easy to distinguish between things that are IT artifacts and things that are not IT artifacts. For example, it should be easy to decide whether the following things qualify as IT artifacts: a Roomba robotic vacuum cleaner, a supply chain that uses IT, a planning system that uses IT, a distributed virtual team, a software development project, a theory about IT-enabled systems, an econometric analysis of smartphone adoption, and a method for motivating computer industry workers. Each of those things might qualify as an IT artifact based on the foregoing definitions even though the identity of shared characteristics that put them in the same category are not evident, to say the least.

Based on the examples above, the statement "My research involves IT artifacts" is meaningless except in differentiating that research from things that IS researchers tend not to study, such as British novels, the behavior of cats, and paintings of the $14^{\text {th }}$ century.

Beyond its lack of specificity, the term IT artifact implies that whatever is being discussed is an instance of IT or fundamentally is about IT. In other words, it implies that just one of an artifact's many essential components defines its essence. Modern refrigerators and automobiles require both electricity and IT to operate. No one calls them electricity artifacts and no one should call them IT artifacts because they are neither about electricity nor about IT. In the same way, there is no reason to apply the label IT artifact to rotobic vacuum cleaners, supply chains, virtual teams, simulation models, IT-related projects, analyses of IT adoption, theories about the digital divide, and many other things that use IT or are associated with IT in some way. 


\section{Various artifact-cousins of the IT artifact don't help.}

Perhaps as a response to confusion about the IT artifact, a number of authors have proposed derivative umbrella terms that include the word artifact, such as the IS artifact, sociotechnical artifact, social artifact, information artifact, and ensemble artifact. As a group these terms will be called the "artifact-cousins" of the IT artifact because they share familial attributes. They share the IT artifact's naming convention $\{\mathrm{X}+$ "artifact" $\}$, where $\mathrm{X}$ is a term such as IS, social, or sociotechnical. They share a familial ambiguity of interpretation because they are defined differently or are used differently without formal definition by different authors who are expressing different viewpoints. Also, in one way or another their use in the academic IS discipline often makes them seem like descendents of themes that have been explored for at least several decades in relation to the social construction of technology (e.g., Pinch \& Bijker, 1987; Orlikowski, 1992).

Artifact-cousins will be mentioned here to illustrate issues of interpretation and definition, but not in nearly enough detail to do justice to articles that will be quoted. The point is not about the individual articles, but about whether emphasis on the artifact- cousins is a beneficial direction for further discussion. We start with social artifacts, technical artifacts, and sociotechnical artifacts, and then move to information system artifacts and ensemble artifacts.

Social artifacts, technical artifacts, and sociotechnical artifacts. At least five decades of research on sociotechnical systems have explored the co-existence of the social and technical in operational systems. While describing a related ontology, Guarino et al., 2012, pp. 536-538) said that "most business and social organizations can be seen nowadays as complex sociotechnical systems including three components: technical artifacts, social artifacts, and humans." ... Technical artifacts, like tools and machines, determine what can be done, amplifying and constraining opportunities for action; social artifacts, like norms and institutions, determine what should be done, governing obligations, goals, priorities, and institutional powers. ... Concerning social artifacts, disciplines such as philosophy, sociology, economics and law have provided theories and methods for analyzing, modelling, and designing them."

Other authors have ascribed different definitions to technical artifact and social artifact. For example, the first few pages of hits from Google Scholar searches for "social artifact" reveal that contracts, religious identity, news, mobile handsets, ethics, jobs, childhood, moral beliefs, punishment, and economics all have been viewed as social artifacts. Many uses of that term are distant from the IS field, but others are closer to home. DeSouza et al. (2005) talk about software code as a social and technical artifact and note that this type of dual role "is exhibited not simply 
by technological hardware, but by other "technical" artifacts such as classification schemes and formal representations. Along similar lines, Pathak (2013, p. 2) describes how XBRL should be studied as a social artifact. "Technological artifacts are physical/material as well as social constructions, thus making it plausible to be called social artifacts too. Extensible Business Reporting Language (XBRL) is one such technological artifact functioning as a social construction in the life of an ordinary accountant to a highflying investment banker." In a separate discussion of whether the constitution of technology is separable from context and whether context is separable from technology, Houston \& Jackson (2003, p. 71) describe an "integration" view in which the meanings and uses identified with technology were constructed as a social artifact reflecting the values of society.

Joerges (1996, p. 53) illustrates why the boundary between the social and technical is problematic. "If technical is always social, technical artifacts are social artifacts, but what kind of social artifacts are they? The legal norms governing traffic systems are social artifacts. Highways, automobiles and traffic lights are considered technical artifacts. What about the technical norms regulating road and automobile construction? Are they to be considered technical or social artifacts, or something in between? ... It seems obvious to me that any specification of "technical" should be grounded in the concept of formal rationality, i.e. standardized methods of calculation on which routine actions can be based" (p. 55).

There is also the question of research perspective. For example, Hirschheim et al. (1996) notes that "different research communities accept alternative ontologies for information systems in the sense that for some communities information systems are only technical artifacts (Denning et al., 1989) while for others they are also social artifacts, i.e. information systems include elements from the language and/or organization domains (Winograd \& Flores, 1986; Floyd et al., 1992).

The term sociotechnical artifact started to appear around 2004 (only 30 hits in a Google Scholar search). Miller (2013, p. 57) says, "a sociotechnical system includes a technological artifact (such as a computer, cell phone, or car), plus the people, social customs, infrastructure, regulations, and protocols associated with that artifact. A refrigerator is a sociotechnical artifact, but it makes no sense to have a refrigerator without electrical power, retail outlets that sell food requiring refrigeration, and people who prefer such food." Similarly, Silver \& Markus (2013, p. 82) says that "so-called" IT artifacts have both technical and social design features and are therefore better regarded as "sociotechnical artifacts". (p. 82). As noted by Goldkuhl (2013, p. 91) "Silver \& Markus (2013, p. 83) write that "user training is a social feature of a sociotechnical artifact, not something that 'accompanies' it." Goldkuhl continues, "Seeing activities like user training and even people as part of the sociotechnical 
artifact blurs the boundaries of the artifact. I also find their distinction of the social and technical as problematic. Software and data are entirely placed in the technical sphere."

The order of citations in the paragraphs above was designed to illustrate that it is easy to construct strings of quotations about social artifacts, technical artifacts, and sociotechncal artifacts that seem to go in circles. To some extent it appears that sociotechnical and technical artifacts are also social artifacts, and that some things that might be considered social artifacts, such as complex processes, contracts, languages, or classification schemes might be viewed as technical artifacts. The ideas can be sorted out in various ways, depending on how one wants to do the sorting and what one wants to include in the sort.

Information system artifact. Lee et al. (2013, pp. 1-2) take the artifact-cousins a step further by proposing that the IT artifact can be superseded by the IS artifact. 'We 'unpack' what has been called the 'IT artifact' into a separate 'information artifact' and 'technology artifact' that, together with a 'social artifact,' interact to form the 'IS artifact.' ... We offer a conceptualization of an IS artifact as itself a system, consisting of subsystems that are (1) a technology artifact, (2) an information artifact, and (3) a social artifact, where the whole (the IS artifact as a system) is greater than the sum of its parts (the three constituent artifacts as subsystems). ... When the three artifacts, just defined, are brought together and interact, they can come to form what we call an IS artifact." Without going into details, one might wonder whether an IS artifact (defined above as a system) is an information system. If so, what is the benefit of introducing the term IS artifact? If not, what is the difference between an IS artifact and an information system? Further, in what sense is an information artifact (defined above as a subsystem) actually a system? For example, an invoice would probably be viewed as an information artifact, but it probably would not be viewed as a system.

Ensemble artifact. Sein et al. (2011) introduces the idea of ensemble artifact as part of a discussion of "action design research," which recognizes that ensembles of hardware and/or software usually evolve over time though adaptation and reconfiguration, eventually diverging from whatever a designer originally proposed. "By ensemble artifact, we specifically mean the material and organizational features that are socially recognized as bundles of hardware and/or software (Orlikowski and Iacono 2001)." (Sein et al., 2011, p. 38) ... "While the researcher may guide the initial design [during action design research], the ensemble artifact emerges through the interaction between design and use. This means that the artifact must eventually reflect intended as well as unintended organizational consequences." (pp. 39-40) ... Ensemble artifacts are dynamic and emerge from the contexts of both their initial design and continual redesign via organizational use." (p. 52). While the evolution of designed artifacts obviously is an important topic in the IS 
field, just the concept of change raises questions about when a particular artifact no longer has its original identity and should be viewed as a different artifact. And as with the introduction of the IS artifact, it is not clear what is gained by creating a new artifact-cousin whose meaning is far from straightforward.

Each of the articles mentioned above addresses important aspects of the combined social and technical nature of things that involve IT in some way. When viewed in combination, they illustrate that the artifact-cousins provide little specificity and tend to blur into each other, harkening back to discussions of the social construction of technology. Along those lines, a paper trying to assess the extent to which the academic IS field has been faithful to the sociotechnical paradigm states that "the IT artifact and the social artifacts cannot (and should not) be distinguished (because they are entangled), just as the human body cannot be separated from the heart and its functions." (Sarker et al., 2013, p. 15)

Also problematic is the assumption that social or sociotechnical components must be present in "IT artifacts" or in IS research. While context, usage, and social issues are important in understanding most of the systems that I tend to focus on, that does not imply that every IS researcher must focus on sociotechnical phenomena. Much valuable research that is relevant to information systems focuses on technical artifacts whose meaning is realized through contributions to other technical artifacts that end users will never see. An example is the "process artifacts" (MotahariNezhad et al., 2011; Lins et al., 2012) that are produced by research related to conceptual modeling, service oriented architectures, and the technical aspects of business process management (BPM) research.

Overall, there is no direct benefit from recognizing that technical artifacts can be viewed as social artifacts while assuming simultaneously that technical artifacts differ from social artifacts or sociotechnical artifacts. Fully appreciating the social and sociotechnical nature of many phenomena is obviously important. For example, automobiles and refrigerators (mentioned earlier) are technical entities that are created through social processes and whose meaning is socially constructed. Likewise, fully appreciating the way designed artifacts evolve over time, often beyond what the designer initially imagined or proposed, is obviously important and obviously should be accepted as a significant IS research topic. This was noted explicitly when Orlikowski and Iacono (2001, p. 131) said that IT artifacts are not static or unchanging, are neither fixed nor independent, and are always embedded in some time, place, discourse, and community. The significance of those ideas is not a reason to create and perpetuate a set of labels that are probably unnecessary and seem to be interpreted in ways that lead in circles. There is little progress in the repeated re-discovery of the taken-for-granted inadequacy of seeing technical artifacts as nothing more than a set of device features and functions. Similarly for the 
repeated re-discovery of the fact that technical and social artifacts change over time, which leads to questions about whether a technical or social artifact viewed today should be seen as an update of an artifact that was designed in the past or as a totally different artifact.

\section{Filling the void left by the retirement of the IT artifact}

Since I propose the retirement of "the IT artifact" and its cousins, I should suggest appropriate ways to fill whatever real or imagined void that retirement would produce. The following three proposals describe different ways to fill the void. The first suggests replacing "the IT artifact" with one of two very simple labels when identifying an IS research topic. The second approach provides guidelines for using or avoiding the use of a number of concepts whose name includes the word artifact. The third and most ambitious proposal tries to address the underlying issues by providing an integrated approach for being specific about the meaning of related concepts.

\section{Proposal 1: Old wine, newly labeled bottles}

Assume that "the IT artifact" doesn't mean anything in particular and that the artifact-cousins tend to blur into each other. A simple way to deal with the retirement of the IT artifact is to use new labels that are simple, clear, and do not require elaborate rationalization. I think that just two labels suffice, TRT and TTBD.

The research topic (TRT). The most awkward and least English-like references to "the IT artifact" are generally of the following type: "In this study the IT artifact is the perceived intention to apply cloud computing in a commercial crowdsourcing environment." While that "perceived intention" might or might not be a plausible research topic for IS researchers, saying that the "perceived intention" is "the IT artifact" does not sound like English and does not clarify anything. It is much simpler and clearer to use the TRT label and say "The research topic is .....," and to be clear why that is a meaningful IS research topic.

The thing being designed (TTBD). Design research is about designing, creating and testing something new that has value to researchers or practitioners. Instead of talking about IT artifacts, sociotechnical artifacts, or other types of artifacts in that type of situation, it is clearer to talk about the thing being designed, created, and tested (TTBD). That label encompasses the various types of topics that are included in design research, e.g., constructs, models, methods, or instantiations (Hevner et al., 2004). Its application to sociotechnical entities such as virtual teams and supply chains avoids confusion about whether those things are artifacts, and instead goes 
directly to issues about whether and how the idea of design research genuinely applies to virtual teams, supply chains, and other things that will change regardless of what researchers designed or intended.

Reverting to just two labels removes confusing terminology from debates about which research topics belong in the IS discipline. I think that is a good idea, but it would be useful to go further.

\section{Proposal 2: Guidelines for making sense of artifacts, IT and otherwise}

The following bullet items are guidelines for making sense of artifacts, regardless of whether we might think of them as IT artifacts or some other type of artifact that is relevant to IS research.

- When using the term artifact, use it in a way that is reasonably consistent with its use in everyday speech. The basic definitions in the MerriamWebster dictionary (www.merriam-webster.com) are 1) "a simple object (such as a tool or weapon) that was made by people in the past" and 2) "an accidental effect that causes incorrect results." The definition from the Cambridge Dictionaries Online (dictionary.cambridge.org) is "an object made by a person, such as a tool or decoration, especially one that is of historical interest." Other online dictionaries contain between two and five similar definitions.

- Use the term artifact only when the content and boundaries of that artifact are reasonably clear and not controversial.

- Don't use "the IT artifact" because that term doesn't communicate anything in particular.

- Don't call something an IT artifact just because it contains or uses IT. For example, calling an airplane or a highly automated manufacturing process an IT artifact is confusing because neither of those things is fundamentally about IT.

- Don't use "the social artifact" or "the technical artifact" as blanket terms that refer to social or technical components of situations or systems in which a number of people and a variety of technologies are present. In such cases, the content and boundaries of "the social artifact" and "the technical artifact" are unclear.

- There is no problem with occasional references to technical artifacts or social artifacts if those terms refer to something specific in a specific context.

- Recognize that information systems have a dual nature and can be researched from both technical and sociotechnical viewpoints. Many, if not most researchers who take a technical perspective recognize fully that context and 
usage matter at the time of application, but choose not to emphasize those points when they focus on automated aspects of information systems. Topics for that research include service oriented architecture, technical languages (such as BPMN and BPEL) related to business process management (BPM), and the design and development of specialized methods and apps that perform automated work.

- Recognize that totally automated systems are increasingly relevant for understanding business operations (e.g., Davenport \& Harris (2005), Taylor \& Raden (2007), Brynjolfsson \& McAfee (2011; 2014). Going beyond sociotechnical issues related to whether or how users use IT within sociotechnical systems, it is increasingly important to study whether or how automated systems perform substantial types of work without direct human involvement other than in creating and installing the systems. Regardless of how often we repeat to each other that the IS discipline deals with sociotechnical systems, an increasing number of those systems are becoming totally automated.

- Recognize the difference between an artifact and its use. An artifact is a thing. Its use is a set of purposeful actions in a context. Using the same term to refer to things and actions is confusing.

- Recognize the difference between an artifact and the path through which it was created or through which its current form evolved. The creation of artifacts and the paths through which they evolve are central topics in the IS field. That does not imply that we should blur the distinction between an artifact and how it evolved. Similarly, artifacts reflect important aspects of the knowledge and interests or their designers. That does not imply that their designers play an active role when those artifacts are used by people who never had contact with the designers and have no idea who they were.

- Recognize that artifacts may change over time in a variety of ways, depending partly on the essence of the artifact. An artifact that is a configuration of hardware and software may change over time as technicians fix bugs and add features and as technicians and users change configuration parameters or append other components such spreadsheets and new usage procedures. If "the artifact" of interest is a sociotechnical system that includes human participants, then it may change through adaptations, bricolage, workarounds, staffing changes, and other reflections of human agency that may be unrelated to what the designers or managers wanted or imagined.

- Recognize that using the term artifact to describe social and sociotechnical systems, regardless of how they are named, almost automatically bumps into definitional questions about when the initial artifact becomes a different 
artifact. This raises questions about what is meant when someone claims to have designed an artifact that is a sociotechnical system that includes human participants. The discussion of ensemble artifacts in Sein et al. (2011) fully recognizes the fact that sociotechnical systems change over time but is not so clear about how the term "ensemble" illuminates situations in which something designed and created during one time period eventually becomes something else.

- Avoid using the IT artifact's artifact-cousins when a commonly used term expresses the same the underlying idea.

-- An IS artifact is an information system except when it is a result of an information's system's operation, in which case some other term should be used.

-- A sociotechnical artifact is a sociotechnical system unless it means an effect of a sociotechnical system, in which case some other term should be used.

-- A technical artifact is a particular thing whose essence involves technology. It should be called a laptop computer or a computer network or a configuration of hardware and software if that is what it is, especially since calling it an IT artifact or technical artifact is nothing more than an unclear reference to something specific. On the other hand, as mentioned earlier, occasional references to technical artifacts are not problematic if the term refers to specific things in specific contexts.

-- A social artifact could be so many types of things that that term should not be used as an analytical concept or as a way to explain distinctions between things that are social and versus things that are technical.

-- The concept of "ensemble artifact" is defined in a way that is usually not associated with artifacts in everyday English. That term should be replaced with something else that is easier for most people to understand.

\section{Proposal 3: Sidestep the IT artifact and lay claim to IT-enabled systems in organizations.}

A decade ago I responded to Benbasat \& Zmud (2003) by suggesting "systems in organizations" an alternative to their notion that the IS discipline is about the IT artifact and its immediate nomological net. (Alter, 2003). Systems in Organizations: Features \& Bugs was the title of Markus (1984). My personal attempt to develop the idea of systems in organizations produced a broadly applicable set of concepts called work system theory (WST), plus a number of extensions beyond the core of WST (Alter, 2013). Among other things, WST provides a way to sidestep the concept of IT artifact in the future.

WST defines a work system as a system in which human participants and/or machines perform work (processes and activities) using information, technology, 
and other resources to produce specific products/services for specific internal and/or external customers. WST covers both a static view of a work system during a period when it is relatively stable and a dynamic view of how a work system changes over time through a combination of planned change (projects) and unplanned change (adaptations, local experimentation, and workarounds). The static view is represented in the work system framework. The dynamic view is represented in the work system life cycle model. The basic ideas of WST have been built into many versions of the work system method (WSM) for analyzing systems in organizations. Work systems are assumed to sociotechnical by default, although the definition of work system includes totally automated systems. Extensions of WST include work system principles, work system design spaces, a metamodel that re-interprets the work system framework for detailed analysis, greater incorporation of service concepts, clarification of the limits of user involvement, a theory of workarounds, and other applications of the core ideas.

I believe that the IS field would benefit from recognizing that it is largely about ITenabled systems in organizations regardless of repeated references to IT artifacts (Alter, 2003). Here is how WST might fill any imagined void if we retire the IT artifact and its artifact-cousins.

- IT artifact. In WST, technology includes both tools that are used by work system participants and automated agents that perform totally automated activities. That takes care of the IT artifact if it is meant as a configuration of hardware and software. If the IT artifact is meant as anything that may be of interest to an IS researcher, then it may or may not be covered by WST or one of his extensions.

- IS artifact. An information system is a work system all of whose activities are devoted to processing information. (Alter, 2013). WST covers the IS artifact if that term means information system with human participants or totally automated information system. If IS artifact means something else, then it may or may not be covered by WST or one of his extensions.

- Sociotechnical artifact. WST covers sociotechnical systems that can be described as performing activities to produce products/services for customers. It might cover other sociotechnical systems, but probably not as usefully.

- Technical artifact. Technologies is an element of the work system framework, which identifies nine elements of a basic understanding of work system. Most nontrivial work systems use a number of different technologies that might be viewed as tools used by users or as automated agents that perform work autonomously once launched. 
- Information artifact. Information is an element of the work system framework. All work systems use and create information. Most use many different types of informational entities, such as transaction data, goals, plans, and rules. These might be discussed in relation to their meaning or in relation to their technical form, e.g., database or repository.

- Social artifact. Participants is an element of the work system framework. All work systems that are not totally automated have participants (i.e., who may or may not be users of technologies). People design, implement, and maintain both sociotechnical and totally automated work systems. The work systems themselves and the work systems related to creating, implementing, and maintaining them might or might not be considered social artifacts, depending on what social artifact means.

- Ensemble artifact. Work systems evolve over time through a combination of planned and unplanned change. A work system whose evolution was influenced significantly by an action design research project (Sein et al., 2011) might be viewed as an ensemble artifact. WST does not address distinctions between a work system that evolves over time and a work system that evolves over time as part of an action design research project. It does address the question of the work system's identity, however, by implying that each iteration through the phases in work system life cycle leads to a different version of the work system.

The above list shows that the IT artifact and various artifact-cousins can be interpreted in relation to a work system perspective that has been explained elsewhere in substantial depth. Although far beyond the current scope, it would be interesting to explore whether and how the IT artifact and various artifact-cousins might be interpreted from other perspectives, such as general systems theory (e.g., Churchman, 1979; Ackoff, 1981; Skyttner,2005), organizational routines (Feldman and Pentland, 2003), practice theory (Feldman and Orlikowski, 2011), sociomateriality (Orlikowski and Scott, 2008), actor network theory (Callon, 1986; Rose et al., 2005) and activity theory (Engeström, 1990; Kaptelinin and Nardi, 2006).

\section{Conclusion}

It is not apparent to me why the IS discipline needs to use the terminology of IT artifacts, IS artifacts, information artifacts, social artifacts, and ensemble artifacts, not to speak of big data artifacts, crowdsourcing artifacts, and cloud computing artifacts. The examples cited here illustrate that the IT artifact and its artifact-cousins 
may be meaningful to some researchers but just as easily might be confusing to others and totally meaningless to practitioners. It makes sense to retire the IT artifact and all derivative terms. Someone talking about a model should talk about that model, not a model artifact. Someone talking about a group of virtual teams should talk about that group of virtual teams, not a virtual team artifact. Someone talking about a sociotechnical system should talk about that sociotechnical system, or might use some other term that has specific associations, such as organizational routine, activity system, or work system. Broad generalizations about technology, IT artifacts, or any of the artifact-cousins should be viewed with skepticism unless there is a clear context and a clear empirical or theoretical basis for the generalizations.

Finally, retiring the IT artifact and its artifact-cousins will represent progress in the academic IS discipline's longstanding struggles with rigor, relevance, and influence. The retirement will be a step toward greater rigor because it will discourage the use of terminology that has contradictory meanings and sometimes seems intentionally vague. It will encourage relevance by channeling effort toward more useful topics. Also, the retirement may contribute to greater influence of the academic IS discipline by encouraging researchers to focus more directly on empirical, theoretical, and design research that has a chance of being seen, appreciated, and perhaps even used by practitioners.

\section{References}

Ackoff, R. (1981) Creating the Corporate Future, New York: John Wiley \& Sons.

Agarwal, R., \& Lucas Jr, H. C. (2005). The information systems identity crisis: Focusing on high-visibility and high-impact research. MIS Quarterly, 29(3), 381-398.

Alter, S. (2003) Sidestepping the IT artifact, scrapping the IS silo, and laying claim to "systems in organizations". Communications of the Association for Information Systems 12, 494-526.

Alter, S. (2013). Work System Theory: Overview of Core Concepts, Extensions, and Challenges for the Future. Journal of the Association for Information Systems, 14(2), 72121.

Benbasat, I., \& Zmud, R. W. (2003). The identity crisis within the IS discipline: Defining and communicating the discipline's core properties. MIS Quarterly, 27(2), 183-194.

Brynjolfsson, E., \& McAfee, A. (2011). Race against the machine: How the digital revolution is accelerating innovation, driving productivity, and irreversibly transforming employment and the economy. Lexington, MA: Digital Frontier Press.

This manuscript was revised for publication in Information System Journal. The revision was published online on Sept. 10, 2014. 
Brynjolfsson, E., \& McAfee, A. (2014). The Second Machine Age: Work, Progress, and Prosperity in a Time of Brilliant Technologies. WW Norton \& Company.

Callon, M. 1986. "Some Elements of a Sociology of Translation: Domestication of the Scallops and the Fishermen of Saint Brieuc Bay." In J. Law (ed.) Power, Action and Belief: A New Sociology of Knowledge? London: Routledge, 196-233

Carroll, L. (1917). Through the looking glass: And what Alice found there. Rand, McNally. (first published in 1872)

Churchman, C. W. (1979) The Design of Inquiring Systems: Basic Concepts of Systems and Organizations, New York, Basic Books

Davenport, T. H., \& Harris, J. G. (2005). Automated decision making comes of age.MIT Sloan Management Review, 46(4), 83-89.

Denning, P., Comer, D., Giles, D., Mulder, M., Tucker, A. Turner, A.J. \& Young, P. (1989). Computing as a discipline: Final report of the task force on the core of computer science. Communications of the ACM, January, 9-23.

De Souza, C., Froehlich, J., \& Dourish, P. (2005). Seeking the source: software source code as a social and technical artifact. In Proceedings of the 2005 international ACM SIGGROUP conference on Supporting group work, 197-206). ACM.

Engeström, Y. (1990) Learning, Working, and Imagining: Twelve Studies in Activity Theory. Helsinki: Orienta-Konsultit Oy.

Feldman, M.S. and Pentland, B.T. (2003) "Re-theorizing organizational routines as a source of flexibility and change." Administrative Science Quarterly, 48, 94-118.

Feldman, M. and Orlikowski, W. (2011) "Theorizing Practice and Practicing Theory," Organization Science, 22(5), 1240-1253.

Floyd, C., Zullighoven, H., Budde, R. \& Keil-Slavik, R. (1992). Software development and reality construction. Berlin:Springer.

Goldkuhl, G. (2013). The IT artefact: An ensemble of the social and the technical?-A rejoinder. Systems, Signs \& Actions, 7(1), 90-99..

Gregor, S., \& Hevner, A. R. (2011). Introduction to the special issue on design science. Information Systems and E-Business Management, 9, 1-9

Guarino, N., Bottazzi, E., Ferrario, R., \& Sartor, G. (2012). Open ontology-driven sociotechnical systems: Transparency as a key for business resiliency. In Information Systems: Crossroads for Organization, Management, Accounting and Engineering (pp. 535542). Physica-Verlag HD.

This manuscript was revised for publication in Information System Journal. The revision was published online on Sept. 10, 2014. 
Hevner, A., March, S. T., Park, J., \& Ram, S. (2004). Design science in information systems research. MIS Quarterly, 28(1), 75-105.

Hirschheim, R., Klein, H. K., \& Lyytinen, K. (1996). Exploring the intellectual structures of information systems development: a social action theoretic analysis.Accounting, Management and Information Technologies, 6(1), 1-64.

Houston, R., \& Jackson, M. H. (2003). Technology and context within research on international development programs: positioning an integrationist perspective.Communication Theory, 13(1), 57-77.

ICIS 2013 Website (2013) IT Artifact, viewed on Jan. 15, 2014 at http://icis2013.aisnet.org/index.php/tracks/104-it-artifact

Joerges, B. (1996). Large technical systems and the discourse of complexity.Ingelstam. L. (1996), Complex Technical Systems, Swedish Council for Planning and Coordination of Research, Stockholm: Affärs Litteratur 55-72

Kaptelinin, V. and Nardi, B.E. (2006), Acting With Technology: Activity Theory and Interaction Theory, Cambridge: MIT Press

Lee, A. S., Manoj, A. T., \& Baskerville, R., L. (2013) .Going Back to Basics in Design: From the IT Artifact to the IS Artifact AMCIS 2013.

Lins, F., Damasceno, J., Souza, A., Silva, B., Aragão, D., Medeiros, R., \& Rosa, N. (2012). Towards Automation of SOA-Based Business Processes. International Journal of Computer Science, Engineering and Applications, 2(2).

March S., \& Smith, G. (1995). Design and natural science research on information technology. Decision Support Systems, 15, 251-266.

Markus, M. L. (1984). Systems in organizations: bugs \& features. Boston, MA: Pitman.

Markus, M. L., \& Silver, M. S. (2008). A foundation for the study of IT effects: A new look at DeSanctis and Poole's concepts of structural features and spirit. Journal of the Association for Information Systems, 9(10), 609-632.

Matook, S., \& Brown, S. A. (2008). Conceptualizing the IT Artifact for MIS research. In 24th International Conference on Information Systems ICIS 2008 (Vol. 14, No. Paper 102, pp. 1-11). Association for Information Systems.

Miller, K. W. (2013). A Secret Sociotechnical System. IT Professional, 15(4), 0057-59.

Motahari Nezhad, H. R., Benatallah, B., Casati, F., \& Saint-Paul, R. (2011). From business processes to process spaces. Internet Computing, IEEE, 15(1), 22-30. 
Orlikowski, W. J. (1992). The duality of technology: Rethinking the concept of technology in organizations. Organization science, 3(3), 398-427.

Orlikowski, W. J., \& Iacono, C. S. (2001). Research commentary: Desperately seeking the" IT" in IT research-a call to theorizing the IT artifact. Information systems research, 12(2), 121-134.

Orlikowski, W. J., and Scott, S. V. (2008) "Sociomateriality: Challenging the Separation of Technology, Work and Organization," Academy of Management Annals, 2(1), 433-474.

Overbye, D. (2014) Over the Side with Old Scientific Tenets, New York Times, Jan. 14, 2014.

Pathak, J. (2013). Extensible Business Reporting Language (XBRL): A Note on Need to Study XBRL as a Social Artifact. International Journal of Enterprise Information Systems (IGI). (forthcoming)

Pinch, T. J., \& Bijker, W. E. (1987). The Social Construction of Facts and Artifacts: Or How the Sociology of. The Social Constructions of Technological Systems: New Directions in the Sociology and History of Technology, 17.

Rose, J., Jones, M. R., \& Truex, D. 2005. "Socio-Theoretic Accounts of IS: The Problem of Agency," Scandinavian Journal of Information Systems 17(1) 133-152.

Sarker, S., Chatterjee, S., \& Xiao, X. (2013). How "Sociotechnical" is our IS Research? An Assessment and Possible Ways Forward. In The 34th International Conference on Information Systems. ICIS 2013.

Sein, M. K., Henfridsson, O., Purao, S., Rossi, M., \& Lindgren, R. (2011). Action Design Research. MIS Quarterly, 35 (1), 37-56

Silver, M., \& Markus, L. (2013). Conceptualizing the SocioTechnical (ST) Artifact. Systems, Signs \& Actions, 7(1), 82-89.

Skyttner, L. (2005) General Systems Theory: Problems, Perspectives, Practice, Singapore: World Scientific Publishing

Taylor, J., \& Raden, N. (2007). Smart Enough Systems: How to Deliver Competitive Advantage by Automating Hidden Decisions. Pearson Education.

Winograd, T. \& Flores, K.E (1986). Understanding computers and cognition. Norwood, NJ: Ablex. 